\title{
A Comparative Study on the Microstructures and Mechanical Properties of Al 6061 Alloy and the MMC Al 6061/TiB $2 / 12_{P}$
}

\author{
T.V. Christy ${ }^{1, *}$, N. Murugan ${ }^{2}$ and S. Kumar ${ }^{3}$ \\ ${ }^{1}$ CSI College of Engineering, Ketti, South India \\ ${ }^{2}$ Coimbatore Institute of Technology, Coimbatore, South India \\ ${ }^{3}$ Indian Institute of Technology, Madras, South India \\ *Corresponding Author: tvchristy@gmail.com
}

\begin{abstract}
Al 6061 alloy is widely used for commercial applications in the transportation, construction and similar engineering industries. It possesses excellent mechanical properties in addition to good corrosion resistance due to which the alloy finds extensive application in naval vessels manufacturing. Al-TiB ${ }_{2}$ composite is a metal matrix composite (MMC) that can be manufactured using the in-situ salt-metal reaction. With $\mathrm{TiB}_{2}$ as the particulate addition the properties of $\mathrm{Al}$ 6061 alloy can be greatly improved. A comparison of the mechanical properties and the microstructure of $\mathrm{Al} 6061$ alloy with $\mathrm{Al}-\mathrm{TiB}_{2}$ metal matrix composite containing $12 \%$ by weight $\mathrm{TiB}_{2} \mathrm{p}$ manufactured through the in-situ process was presented.
\end{abstract}

Key Words: Al 6061 alloy, Al-TiB 2 Metal matrix Composite (MMC), Aluminium Matrix Composite (AMC)

\section{INTRODUCTION}

Al alloy Al 6061 is widely used in numerous engineering applications including transport and construction where superior mechanical properties such as tensile strength, hardness etc., are essentially required. A typical chemical composition of Al 6061 is presented in Table 1. Its superior corrosion resistance makes it a suitable candidate material for marine structural applications. The demand for lighter weight, cost effective and high performance materials for 
use in a spectrum of structural and non-structural applications has resulted in the need for fabrication of metal matrix composites (MMCs) of various types.

Table 1. Chemical composition of Al 6061.

\begin{tabular}{ccccccccc}
\hline Element & $\mathbf{M g}$ & $\mathbf{F e}$ & $\mathbf{S i}$ & $\mathbf{C u}$ & $\mathbf{M n}$ & $\mathbf{V}$ & $\mathbf{T i}$ & $\mathbf{A l}$ \\
\hline $\begin{array}{c}\text { Weight } \\
\text { \% }\end{array}$ & 1.08 & 0.17 & 0.63 & 0.32 & 0.52 & 0.01 & 0.02 & Remainder \\
\hline
\end{tabular}

In recent years, the aluminium alloy based MMCs have offered designers many added benefits as they are particularly suited for applications requiring good strength at high temperatures, good structural rigidity, dimensional stability, light weight and low thermal expansion [1-6]. The major advantages of Aluminium Matrix composites (AMCs) include greater strength, improved stiffness, reduced density, improved high temperature properties, controlled thermal expansion coefficient, thermal / heat management, enhanced and tailored electrical performance, improved abrasion and wear resistance and improved damping capabilities [7, 8]. One such MMC is $\mathrm{Al}-$ $\mathrm{TiB}_{2} \mathrm{p}$ containing $\mathrm{TiB}_{2}$ as the dispersed second phase particle. When a molten metal or other liquid phase containing dispersed second phase particles solidifies, interactions take place between the advancing solidification front and the particles. Such interactions affect the front morphology and the particle solidification as well. The solidification front pushes or engulfs the particles. Due to this reason, the particles can be found at the grain boundaries, the interdentritic regions, or within the primary grains themselves. This phenomenon found in many solidification processes was observed by others [9, 10]. The effect of particulate silicon carbide on the mechanical behavior of Al 6061 MMC has been studied previously by T. S. Srivatsan et. al., [11]. The $\mathrm{TiB}_{2}$ particles formed through the in-situ reaction process are found to stick together forming agglomerates. Feng and Froyen also reported a similar finding while preparing the AMC with commercial pure $\mathrm{Al}$ as the matrix [12]. The in-situ based manufacture of the AMC under study was extensively reported in the literature $[12,13]$. However, manufacture of the AMC with $\mathrm{Al} 6061$ as the matrix alloy containing $\mathrm{TiB}_{2} \mathrm{p}$ as the composite material is not widely reported. The objective of the present work is to compare the mechanical properties and microstructure of as cast Al 6061 alloy with that of aluminium MMC with $12 \%$ by weight $\mathrm{TiB}_{2} \mathrm{p}$.

\section{EXPERIMENTAL PROCEDURE}

\subsection{Composite Fabrication}

Due to the various advantages listed above, Al 6061 alloy in as-cast condition was used in this study. The AMC for this work viz., $12 \%$ by weight $\mathrm{TiB}_{2}$ particulates in $\mathrm{Al} 6061$ matrix 
(henceforth referred to as $\mathrm{Al} 6061 / \mathrm{TiB}_{2} / 12 \mathrm{p}$ ) was manufactured at the Department of Mechanical Engineering, CSI College of Engineering, Ooty, South India through the in-situ process involving the salt-metal reaction between the titanium containing $\mathrm{K}_{2} \mathrm{TiF}_{6}$ and the boron containing $\mathrm{KBF}_{4}$ salts in the presence of molten Aluminium 6061 alloy. During the in-situ reaction process, the elements $\mathrm{Ti}$ and $\mathrm{B}$ are introduced from the two salts (mentioned above) into the molten aluminium and made to react within it.

As the salts are mixed stoichiometrically to form $\mathrm{TiB}_{2}, \mathrm{TiB}_{2}$ is the only intermetallic phase to be formed by the reaction. The reaction scheme used to form the composite is given below:

$3 \mathrm{~K}_{2} \mathrm{TiF}_{6}+22 \mathrm{Al}+6 \mathrm{KBF}_{4} \longrightarrow 3 \mathrm{Al}_{3} \mathrm{Ti}+3 \mathrm{AlB}_{2}+9 \mathrm{KAlF}_{4}+\mathrm{K}_{3} \mathrm{AlF}_{6}+$ Heat

$3 \mathrm{Al}_{3} \mathrm{Ti}+3 \mathrm{AlB}_{2} \longrightarrow 12 \mathrm{Al}+3 \mathrm{TiB}_{2}$

Aluminium in the form of rods was melted in an electrical resistance furnace using a graphite clay crucible. The melt was taken to a temperature of $840^{\circ} \mathrm{C}$. The premixed salts were then introduced into the molten aluminum alloy and thoroughly stirred using a graphite rod at intervals of every 10 minutes. The total reaction time allowed at the mentioned temperature was $1 \mathrm{~h}$ and the melt was later poured into a cast iron die for casting a rectangular composite plate of size $10 \mathrm{~cm}$ x $25 \mathrm{~cm}$ as shown in Figure 1. Samples were prepared from the casted composite plate for carrying out metallurgical and mechanical property evaluation studies.

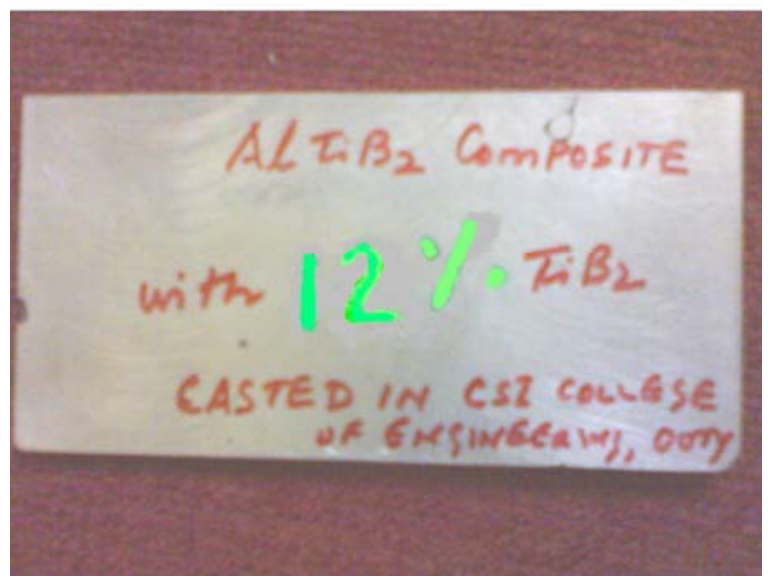

Figure 1. Casted Composite Plate

\subsection{Characterization of $6061 \mathrm{Al}$ alloy and $\mathrm{Al}-\mathrm{TiB}_{2}$ Composite}

Figure 2 shows the X-ray diffraction pattern of the composite depicting the presence of $\mathrm{TiB}_{2}$. Optical microscopic examination was conducted on both aluminium 6061 alloy and Al MMC 
following the standard metallographic procedure. The etchant used was 0.5 vol. \% HF aqueous solution. The photomicrographs taken on the top surface are shown in Figures 3 and 4. The morphologies and microstructures of the fabricated $\mathrm{Al}_{-} \mathrm{TiB}_{2}$ composite as well as the fracture surfaces of the tensile test specimens were observed by scanning electron microscope (Joel JSM 6360) using $\mathrm{Cu}-\mathrm{K} \alpha$ radiation. The scanning electron micrographs and the fractographs taken are shown in Figs. 5-7. The room temperature Brinnell hardness was measured on the top surface of the composite on six locations and the average is presented in Table 2. Six numbers of tensile test samples prepared as per ASTM-E08 standard were tested. The average value of tensile strength obtained is also presented in Table 2.

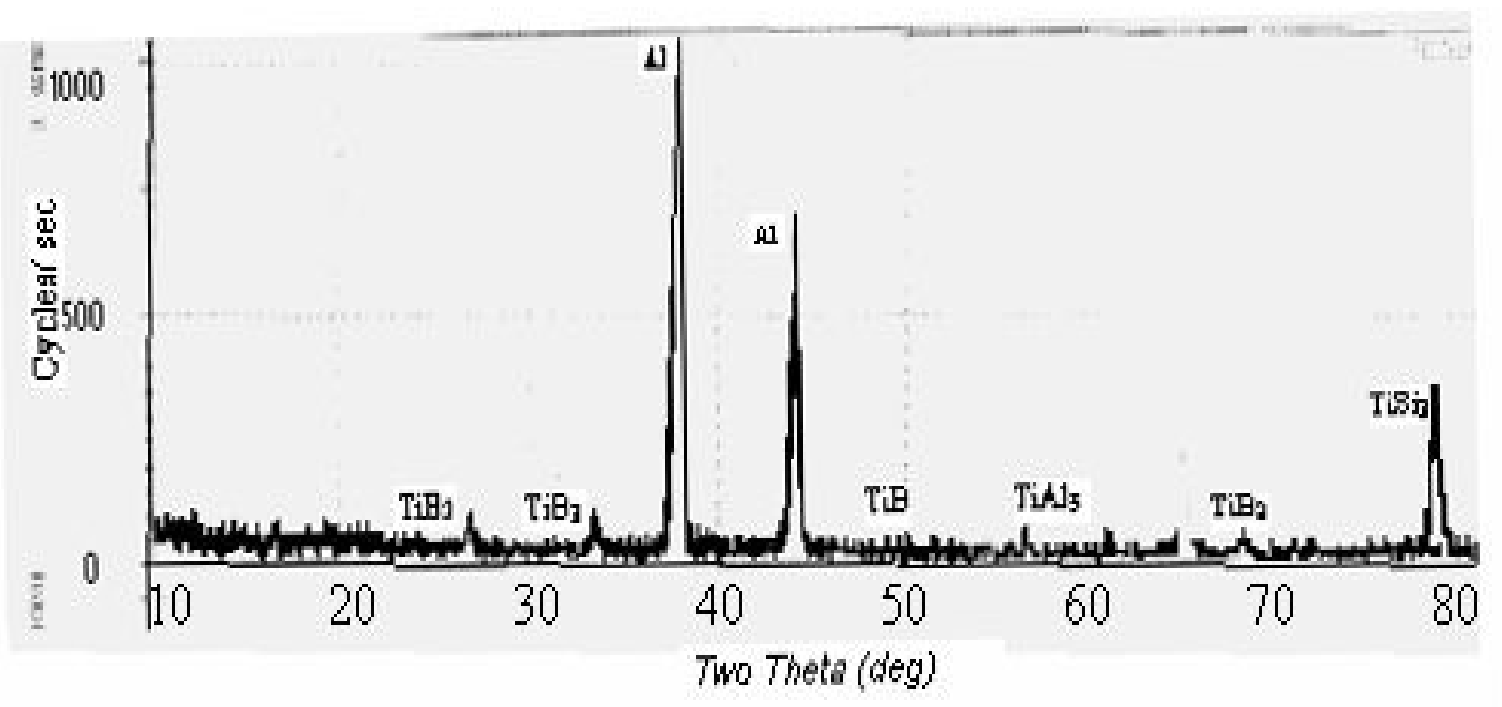

Figure 2. X-ray diffraction pattern of the composite.
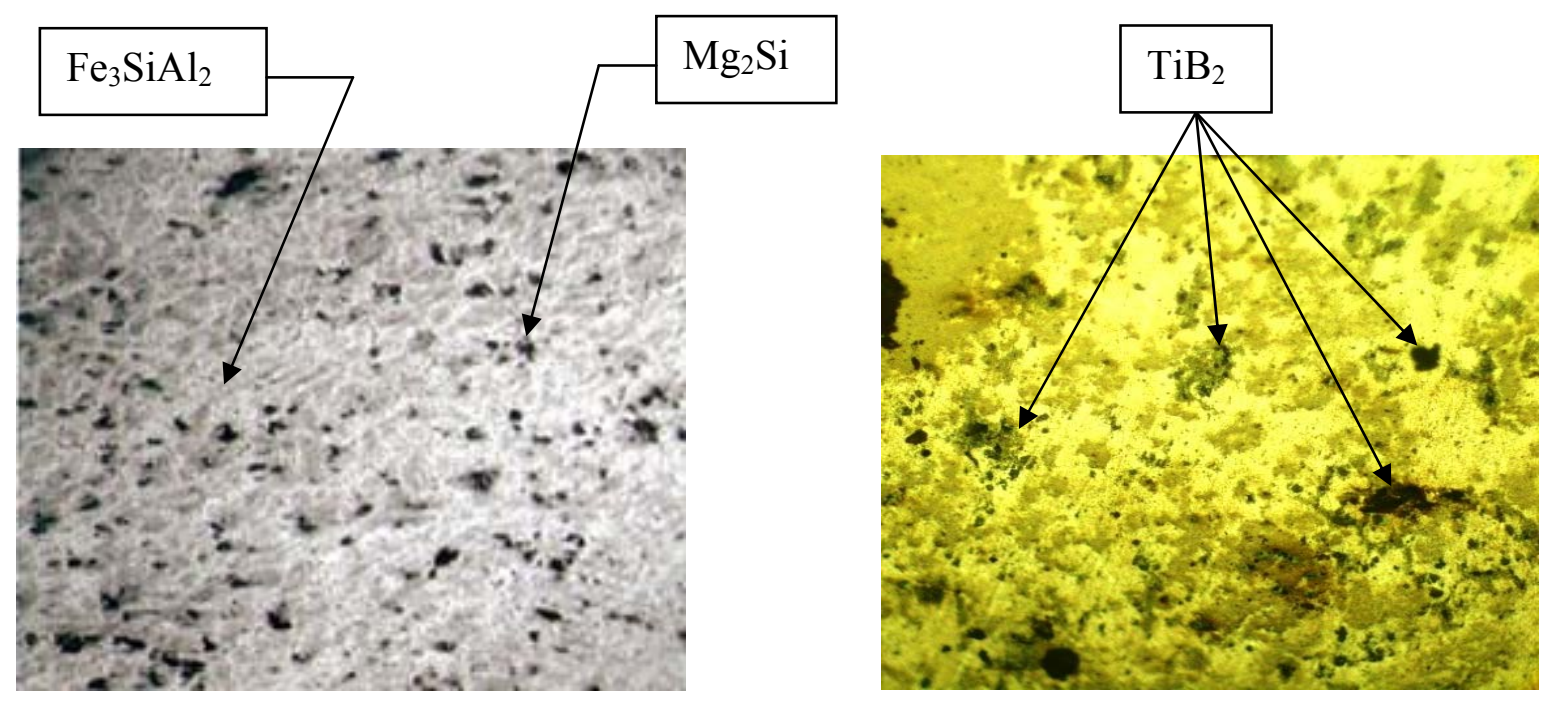

Figure 3. Optical Photomicrograph of Al 6061alloy

Figure 4. Optical Photomicrograph of $\mathrm{Al}-\mathrm{TiB}_{2}$ composite 

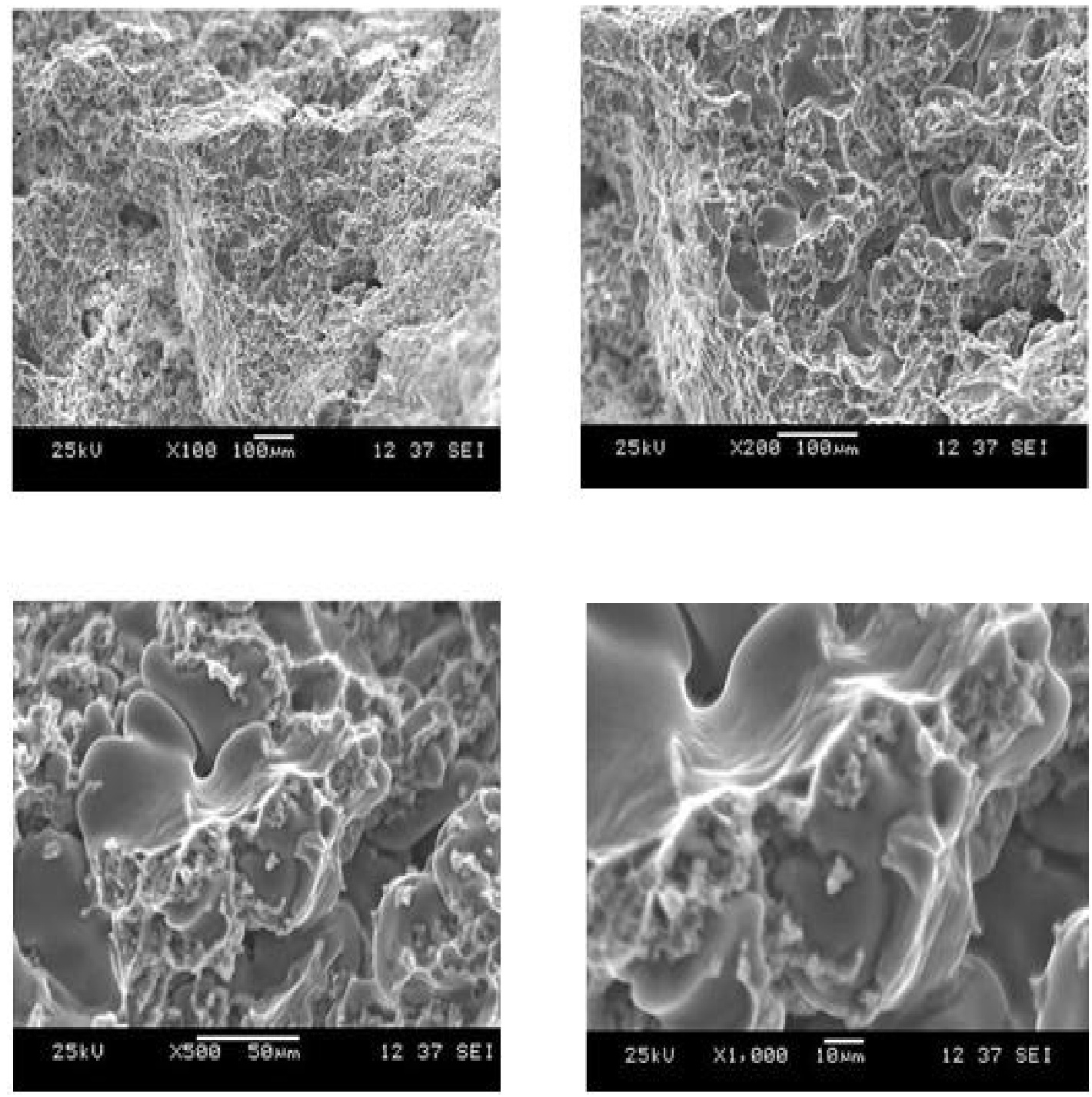

Figure 5. Scanning Electron Micrographs of the Al-TiB2 composite formed through the 'in-situ' reaction.

Table 2. Hardness and Tensile Properties.

\begin{tabular}{lcccc}
\hline Material & Hardness(BHN) & $\begin{array}{c}\text { Tensile } \\
\text { Strength(MPa) }\end{array}$ & $\begin{array}{c}\text { Young's } \\
\text { Modulus(GPa) }\end{array}$ & $\begin{array}{c}\text { \% } \\
\text { Elongation }\end{array}$ \\
\hline $\begin{array}{l}\text { Al-6061 } \\
\text { (as cast) }\end{array}$ & 62.8 & 134.8 & 79.8 & 8.0 \\
\hline $\mathrm{Al}_{-\mathrm{TiB}} \mathrm{p}$ & 88.6 & 173.6 & 94.2 & 7.0 \\
\hline
\end{tabular}




\section{Tensile Fracture}
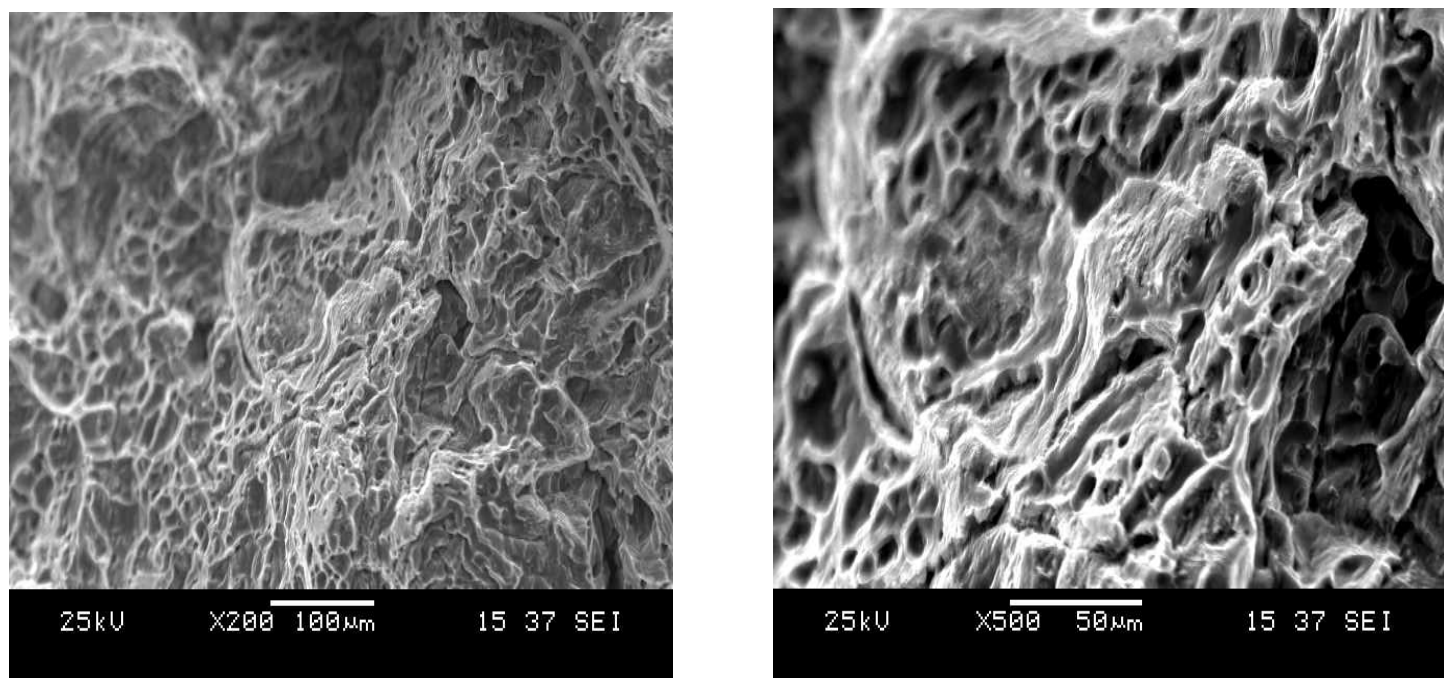

Figure 6. SEM Fractographs of Al 6061.
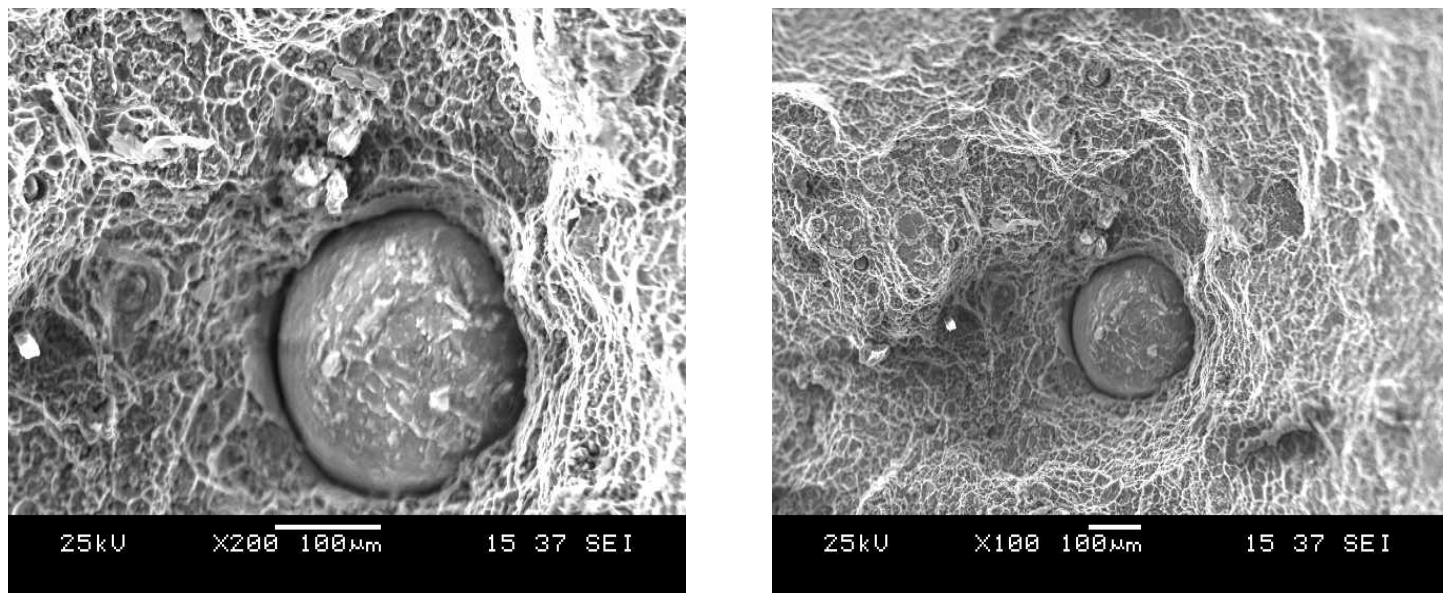

Figure 7. SEM Fractographs of $\mathrm{Al}-\mathrm{TiB}_{2}$ Composite.

\section{RESULTS AND DISCUSSION}

\subsection{Microstructure Characterization}

X-ray diffraction pattern of the composite presented in Figure 2 shows that the composite is consisted of aluminium and $\mathrm{TiB}_{2}$ in addition to traces of $\mathrm{TiAl}_{3}$, TiB and $\mathrm{TiSi}_{2}$. The presence of $\mathrm{TiSi}_{2}$ is mainly due to the use of the graphite clay crucible and the silicon contamination from the 
clay [14]. Since the two salts viz, $\mathrm{K}_{2} \mathrm{TiF}_{6}$ and $\mathrm{KBF}_{4}$ are stoichiometrically mixed to form $\mathrm{TiB}_{2}$, $\mathrm{TiB}_{2}$ is the main intermetallic component formed by the reaction. This is also confirmed by the $\mathrm{XRD}$ analysis.

Figure 3 shows that the microstructure of 6061 aluminium alloy matrix contains $\mathrm{Mg}_{2} \mathrm{Si}$ (black) and $\mathrm{Fe}_{3} \mathrm{SiAl}_{2}$ (grey) particles. Optical microscopic examination of the composite reveals the presence of reinforcement particles in the form of clusters. From Figure 4 it is found that the discontinuous $\mathrm{TiB}_{2} \mathrm{p}$ reinforcement phase being non-uniform in size and irregularly shaped are dispersed randomly through the aluminium alloy matrix. Agglomerations or clusterings of the $\mathrm{TiB}_{2} \mathrm{p}$ reinforcements of varying size and shape are observed resulting in particulate-rich and particulate-depleted regions. Uniformly small and irregularly shaped particles intermingled with larger $\mathrm{TiB}_{2} \mathrm{p}$ of varying size is characteristic of an agglomerated site. Besides the presence of reinforcing $\mathrm{TiB}_{2} \mathrm{p}$, the alloy is found to be rich in coarse insoluble iron-rich and silicon-rich constituent particles, resulting from the presence of impurity elements, i.e. iron and silicon, in the aluminium alloy.

The $\mathrm{TiB}_{2}$ particles formed through the in-situ reaction process are found to stick together forming agglomerates Figs. 4 and 5. The tendency of $\mathrm{TiB}_{2}$ particles to cluster was found to be very significant in the $\mathrm{Al}_{-} \mathrm{TiB}_{2}$ system as reported by Jha and Dometakis [14]. In the present work also, the clustering of $\mathrm{TiB}_{2}$ particles in the $\mathrm{Al}$ matrix was found to be significant. The cause of clustering is yet to be clearly explained. A number of theories so far proposed indicate the contamination of the $\mathrm{TiB}_{2}$ particle surface as the reason for clustering. $\mathrm{Al}_{3} \mathrm{Ti}$ [15], Magnesium [14] and reactive elements (e.g. potassium) from residual salt [15] have been suggested as possible surface active agents. The traveling of the particles into clusters by oxide films has also been proposed [17]. As negligible changes in the composite's microstructure due to increase in holding temperature have been reported [12], the holding temperature was maintained at $840^{\circ} \mathrm{C}$ in the present experiment.

\subsection{Improved Mechanical Properties in the Composite}

It is evident from Table 2 that the composite exhibited a higher hardness than the aluminium alloy. Also, it is found from the table that the composite has a higher tensile strength than 6061 aluminium alloy with reduced ductility. The significant improvement in the mechanical properties of the composite when compared with the aluminium alloy can be attributed to the distribution of $\mathrm{TiB}_{2}$ particles in the matrix.

Figures 6 and 7 show the scanning electron micrographs of the fractured surface of the specimens. The cavities shown in the figures are the locations where the reinforcement particles had resided in the matrix. In general, MMCs often behave asymmetrically in tension and in compression and hence have higher ultimate tensile strength yet lower proportional limits than 
monolithic alloys. Such behavior of the composites lies with the factors governing matrix plasticity which can be divided into two areas: those affecting the stress rate of the matrix and those affecting the flow properties of the matrix through changes in microstructure induced by inclusion of the reinforcement.

\section{CONCLUSIONS}

1. The composite Al-6061/ $\mathrm{TiB}_{2} / 12 \mathrm{p}$ was successfully produced by the in-situ reaction procedure. Strings as well as particulate agglomerates were present as disinct microstructural features of the composite.

2. The manufactured $\mathrm{Al}-\mathrm{TiB}_{2}$ composite exhibited higher values of hardness, tensile strength and Young's modulus than the base alloy.

3. The ductility of the composite was found to be slightly lower than that of the aluminium 6061 alloy.

\section{ACKNOWLEDGEMENTS}

The authors thank the Naval Research Board of India, Defense Research and Development Organization, New Delhi for providing financial support for this research. Thanks and appreciations are also extended to Mr. Prakash, Lecturer in Chemistry, CSI College of Engineering, Ooty, South India, the College Management and the staff of Mechanical Engineering department for providing all physical facilities.

\section{REFERENCES}

1. Sharma, S.C., Girish,B., Kamath, R., and Sathish, B.M., (1999) Fractography, Fluidity and Tensile Properties of Aluminium/Hematile Particle Composite, Journal of Materials Engineering Performance, 8(3): 309-314.

2. Sharma, S.C., Seah, K.H.W., Sathish B.M., and Ginish, B.M. (1996) Effect of Short Glass Fibers on Mechanical Properties of Cast Al6061 Alloy Composites, Material Design, 17(5/6): 245-250.

3. Sharma, S.C. (2000) Albite Particles on the Co-efficient of Thermal Expansion Behavior of the Al6061 alloy Composites, Metallurgical \& Materials Transaction A 31: 773-780.

4. Tjong, S.C., and Ma, Z.Y The High-Temperature Creep Behavior of Al Matrix Composites reinforced with $\mathrm{SiC}, \mathrm{Al}_{2} \mathrm{O}_{3}$ and $\mathrm{TiB}_{2}$ Particles, Composite Science Technology, 57(197): 697702.

5. Akbulut, H., Durman, M., and Yilmaz, F.,(1998) Higher Temperature Young's Modulus of Aluminium Short Fiber Reinforced Al-SiC MMCs Produced by Liquid Infiltration, Composite Science Technology, 14: 299-305. 
6. Seah K.H.W., Sharma, S.C., and Krishna, M., (March 2006) Damping Behavior of Al 6061/Albite MMCs, Journal of ASTM International, 3(3) Paper ID 5A1 12394

7. Bishop, J.E., and Kinar, V.K., (1995) Anlaysis of Electro Thermodynamic Damping in Particle-Reinforced Metal Matrix Composites, Mcfall-Metallurgical Transaction A, 26(a): 2773-2782.

8. Surappa M.K., (Feb/April 2003) Aluminium Matrix Composites: Challenge and Opportunities, Sadhana, 28 (Part1\&2): 319-334.

9. Y. M. Yousef, R.J. Dashwood, P.D. Lee. (2005), Effect of Clustering on Particle Pushing and Solidification Behaviour in $\mathrm{TiB}_{2}$ Reinforced Al PMMCs, Composites 36 (A): 747-763.

10. Morteson. A., Jin,(1992) Solidification Processing of MMCs, International Material Rev. 37(3): 101-28 20.

11. Srivatsan T.S., Meslet Al-Hajai, B. Hotton and P. C. Larn.,(2002) Effect of Particulate Silicon Carbide on Cyclic Plastic Strain Response and Fracture Behaviour of 6061 Aluminium alloy MMC, Applied Composite Materials,9: 131-153.

12. Feng C.F., Froyen, L., (2000) Microstructure of in-situ Al/TiB 2 MMCs Prepared by a Casting Route, Journal of Material Sciences 35: 837-850.

13. Yuyoung chen, Chung, D. D.L. (1996), In-Situ Al-TiB2 Composite Obtained by Stir Casting, Journal of Material science 31: 311-315.

14. Jha. A., Dometakis. C. (1997), The Dispersion Mechanism of TiB 2 Ceramic Phase in Molten Aluminium and its Alloys, Material Design 18(4): 297-301.

15. Schumacher.P., Greer.Al.(1996), High-resolution TEM of Grain-retaining Particles in Amorphous Aluminium Alloys, Proceedings of the International Conference on Light Metals, Warrendale, PA-Minerals, Metals and Materials Society/AIME: pp.745-53.

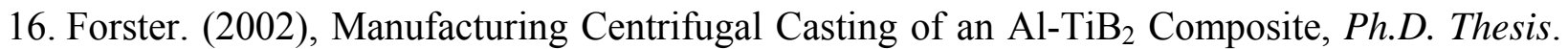
Imperial College, London.

17. Kennedy. A R., Wyayy. SM., (2000) Effect of Processing on the Mechanical Properties and Interfacial Strength of Aluminium TiC MMCs, Composite Science Technology 60(2): 30714. 